\title{
Effectiveness of balloon exercise on level of dyspnoea among patients with lower respiratory tract disorder
}

\begin{abstract}
Background: Breath is the key to health and wellness, a function can learn to regulate and develop in order to improve our physical, mental and spiritual wellbeing. Breathing is one of the most important functions o our body. A person can only live from 5 to 10 seconds without taking another breath. The main function of breathing is to deliver oxygen to our lungs and to remove carbon-di-oxide when necessary which is done by respiratory system. Respiratory disease is a significant chronic health problem in our society. Chronic respiratory disease is found to be one of the most distressful conditions, badly affecting human life.
\end{abstract}

Aim: The main aim of the current study was to assess the effectiveness of the effectiveness of ballooning exercise on level of dyspnoea among patients with lower respiratory tract disorder in medical wards of MGMC\&RI, Puducherry.

Materials and methods: Quantitative research approach was used for this study. The pre-experimental study design was used for this study. Total 20samples were selected using purposive random sampling technique balloon therapy was given for a week. The data pertaining to level of dyspnoea was collected using structured self administered questionnaire and respiratory assessment for dyspnea.

Results: Among 20 patients the level of dyspnea was measured using dyspnoea scale before the implementation of balloon therapy, 15(75\%) patients had poor dyspnea score. Out of 20 samples, $12(60 \%)$ of patients had normal dyspnea scale.

Conclusion: Regular practice of ballooning exercise can improve the respiratory status to a greater extent among patients with lower respiratory disorders.

Keywords: effectiveness, ballooning exercise, dyspnea
Volume 4 Issue 2 - 2017

\author{
Kripa Angelin \\ Department of Medical and Surgical Nursing, Kasturba Gandhi \\ Nursing College, India
}

\begin{abstract}
Correspondence: : Kripa Angeline, Medical and Surgical Nursing Department, Kasturba Gandhi Nursing College, Puducherry, India, Email angelinekripa@gmail.com
\end{abstract}

Received: December 27, 2016 | Published: May 17, 2017

\section{Introduction}

Breath is the key to health and wellness, a function can learn to regulate and develop in order to improve our physical, mental and spiritual wellbeing. Breathing is one of the most important functions o our body. The main function of breathing is to deliver oxygen to our lungs and to remove carbon-di-oxide when necessary which is done by respiratory system. Respiratory disease is a significant chronic health problem in our society. Chronic respiratory disease is found to be one of the most distressful conditions, badly affecting human life. ${ }^{1,2}$ World health organization (2011) shows that by mid-century, morbidity and mortality from respiratory disease will reach record at High levels. The report of "WORLD HEALTH STATISTICS 2011" Says that, 235 million people currently suffer from asthma, $90 \%$ of COPD deaths occur in low and middle income countries and $>3$ million people died of COPD in 2005. The lower respiratory tract infection pneumonia remains that most common infection seen in the community and among hospitalized patient. ${ }^{3,4}$ National Disease Statistics (2011) worldwide shows a high prevalence of respiratory morbidity among patients with respiratory disorders. It says that COPD is the third leading cause of death in America. 12.7 million U.S adults (aged 18 and above) were estimated to have COPD, 10.1 million American reported chronic bronchitis and 4.7 million with emphysema. Most of the disease burden in India is due to the respiratory disorders namely asthma, bronchitis, and tuberculosis (TB) and Pneumonia. In low resource setting these diseases are mainly attributed with exposure to indoor pollution, solid cooking fuels, poor housing, low nutritional status and sanitary condition. The association of respiratory disorder with geographical region may be relevant with population density, industrial and textile pollutants, and tobacco consumption. ${ }^{5}$ Over 35 million people in the United States are living with lung disease and one in seven people die from it each year. Respiratory disease accounts for the $14 \%$ of total expenditure for health care in the United States (Health People, 2010). Flick M.R, Moody LE et al (2011, Swedan) conducted a study on effect of nebulization on arterial oxygen saturation in COPD. 20 patients with mild to severe COPD received ultrasonic nebulization to assess the danger of short term changes in blood gas level during this therapy. The status of arterial oxygenation was monitored during 20 minutes. In all 20 patients pulse oxymetry studies showed only a small mean change at ten minutes of nebulization therapy. ${ }^{6}$ Regular lung exercises can help diminish the breathlessness associated with chronic obstructive pulmonary disease (COPD), but they require expensive training and patient support. A group of British physicians hypothesized that blowing up a balloon could be an inexpensive substitute for such exercises. They tested their hypothesis in a randomized trial of 28 patients with spirometrically documented severe COPD (FEV1 less than 1 liter). Thirteen patients were told to inflate a rubber balloon 40 times a day for eight weeks, and the other 15 served as controls. At the beginning and end of the study, each subject was assessed on three outcome measures: distance walked in six minutes, overall sense of well-being, and self-assessment of breathlessness. At the end of the study, the balloon group showed a 
significant improvement in breathlessness and slight but no significant improvements in walking distance and well-being. ${ }^{7}$

\section{Objectives of the study}

I. To assess the level of dyspnoea among patients with lower respiratory tract disorders during pretest.

II. To evaluate the effectiveness of ballooning exercise on level of dyspnoea among patients with lower respiratory tract disorders during post-test.

III. To find out the association between level dyspnoea of the patient with lower respiratory tract disorders and selected demographic variables.

\section{Methodology}

\section{Research approach}

Experimental research approach was adopted for the study as it was intended to assess the effectiveness of balloon therapy on level of dyspnoea among patient's lower respiratory tract disorders.

\section{Research design}

The design used was single group pre-test, post-test design -pre experimental design.

\section{Study setting}

The study was conducted in Mahatma Gandhi Medical College and Research Institute Puducherry. It is a Multi-Specialty Hospital situated $15 \mathrm{~km}$ away from Puducherry. It is 850 bedded with Specialty Wards

\section{Study population}

The population of the study included patients in male medical ward and female medical ward of MGMC\&RI, who met the inclusion criteria.

\section{Sample and sample size}

Patient admitted in female medical ward and male medical ward and those who fulfill the criteria, where selected as sample. The sample size was 20 .

\section{Criteria for sample selection}

\section{Exclusion criteria}

I. Patient who were not willing to participate

II. Patient with oral lesions

III. Patient who cannot follow the instruction. e.g., deaf and dumb, psychiatric patients and blind patients.

IV. Patient who had chronic disease like cancer, congestive cardiac failure etc...

\section{Inclusion criteria}

I. Patient with age of 20-60 years

II. Both the sexes

\section{Sampling technique}

The samples who met the inclusion criteria during the data collection were selected using Purposive sampling technique. ${ }^{8,9}$

\section{Procedure for data collection}

Before starting data collection researcher obtained permission from the HOD of pulmonary medicine. The sample was selected on the basis of selection of criteria an oral consent was obtained. Pre-test was done on the first day of data collection and post-test was done on the $14^{\text {th }}$ day after the ballooning exercise. Data was collected using observation and interviewing method focusing on the improvement in dyspnoeic state among patients with lower respiratory tract disorder. The data was collected from wards for a period of two weeks. ${ }^{7,10}$

\section{Results}

\section{Background variables}

a. The level of dyspnea was measured using dyspnea scale before the implementation of balloon therapy, $15(75 \%)$ patients had poor dyspnea score.

b. Out of 20 samples, each patient had normal respiratory status after the implementation of balloon therapy when compared to the pre test score. After the implementation of ballooning exercise , $12(60 \%)$ of patients showed normal grading in dyspnea scale

c. There is an association between age, gender, smoking habit and duration of illness with the respiratory status.

d. Considering the age group, $4(20 \%)$ of 20 samples belongs to the age group $20-40 y e a r s, 13(65 \%)$ belongs to the age group 41-60years and 3(15\%) belongs to the age group of $61 \&$ above. There was an association with dyspnea score as the $\mathrm{p}$ value 0.045 which was found to be significant.

e. With respect to the gender, $13(65 \%)$ are male $\& 7(35 \%)$ are female. There is a significant association between gender and respiratory status. There was an association with respiratory rate as the $p$ value 0.058 which was found to be significant.

f. With respect to the smoking habit $8(40 \%)$ are smokers and $12(60 \%)$ were non smokers. There is significant association between smokers and respiratory status. There was an association with dyspnea score as the $\mathrm{p}$ value 0.0035 which found to be significant.

g. With respect to the duration of illness, $10(50 \%)$ belongs to the duration of the illness less than 2 years, $8(40 \%)$ belongs to the duration of illness 2-3 years and 2(10\%) belongs to the duration of illness more than 2 years. There was an association with lung capacity as the p value 0.027 which was found to be significant. ${ }^{11}$

Frequency and percentage distribution of samples with demographic variables (Table Ia-Table If, Table 2 \& Table 3)

Table IA Frequency and percentage distribution of Age and Gender among patients with lower respiratory tract disorders $(\mathrm{N}=20)$

\begin{tabular}{llll}
\hline SI. No & Demographic Variables & Frequency & Percentage \\
\hline I & Age & & \\
& $20-40$ & 4 & 20 \\
& $41-60$ & 13 & 65 \\
& 6I \& above & 3 & 15 \\
& Gender & & \\
& Male & 13 & 65 \\
& Female & 7 & 35 \\
\hline
\end{tabular}


Table IB Frequency and percentage distribution of education and occupational status among patients with lower respiratory tract disorders

\begin{tabular}{llll}
\hline SI. No & Demographic variables & Frequency & Percentage \\
\hline I & Educational status & \\
& Non-literate & 5 & 25 \\
& Primary & 12 & 60 \\
Secondary & 2 & 10 \\
Graduate & 1 & 5 \\
Occupational status & & \\
& $\begin{array}{l}\text { Unemployed } \\
\text { Self employed }\end{array}$ & 5 & 25 \\
$\begin{array}{l}\text { Employment in public } \\
\text { sector } \\
\text { Employment in private } \\
\text { sector }\end{array}$ & 15 & 65 \\
\end{tabular}

Table IC Frequency and percentage distribution of area of work and duration of illness among patients with lower respiratory tract disorder

\begin{tabular}{llll}
\hline SI. No & Demographic variables & Frequency & Percentage \\
\hline 1 & Area of work & & \\
& Cotton industry & 0 & 0 \\
& Chemical industry & 0 & 0 \\
& Mining industry & 0 & 0 \\
& others & 20 & 100 \\
2 & Duration of illness & 10 & 50 \\
& $<2$ years & 8 & 40 \\
$2-3$ years & 2 & 10 \\
& $>2 y e a r s$ & &
\end{tabular}

Table ID Frequency and percentage distribution of types of workers and presence of co-morbid illness among patients with lower respiratory tract disorders.

\begin{tabular}{llll}
\hline SI. No & Demographic variables & Frequency & Percentage \\
\hline 7 & Types of workers & & \\
& Sedentary workers & 5 & 25 \\
& Moderate workers & 12 & 60 \\
& Heavy workers & 3 & 15 \\
& Presence of co-morbid illness & \\
& Anemia & 5 & 25 \\
& Ischemic heart disease & 4 & 20 \\
& Thyroid disorders & 1 & 5 \\
None & 10 & 50 \\
\hline
\end{tabular}

Table IE Frequency and percentage distribution of habit of smoking and tobacco chewing patients with lower respiratory tract disorders

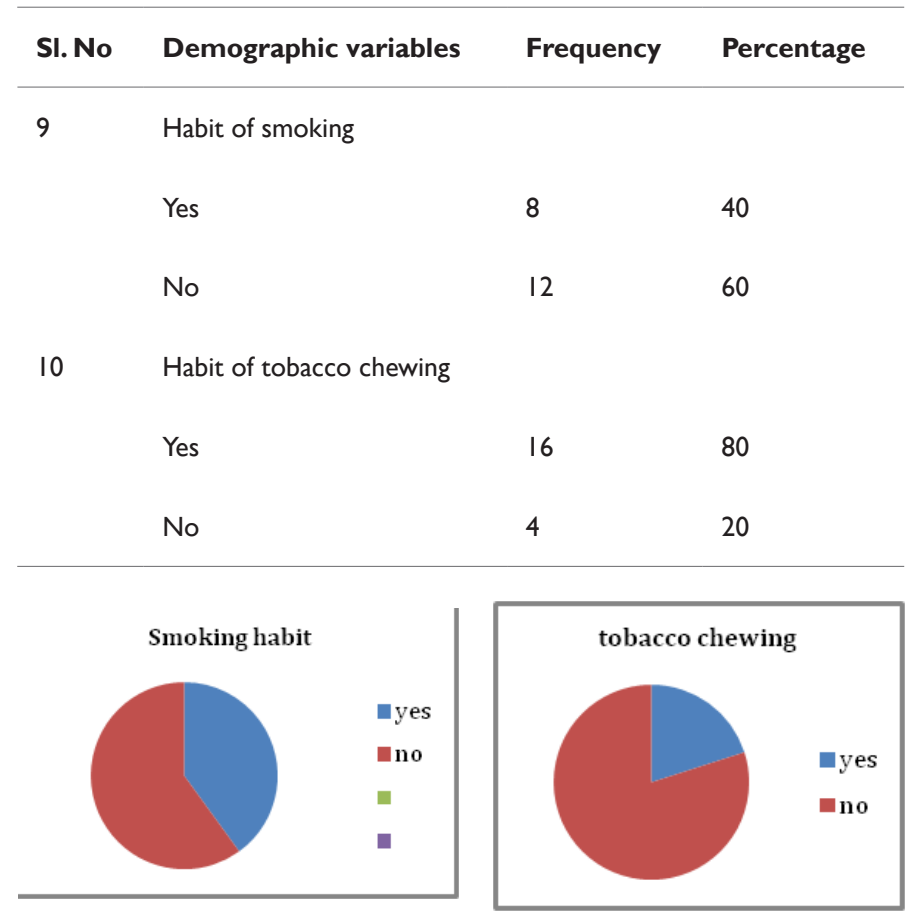

Table IF Frequency and percentage distribution of alternative therapy practices and medication intake among patients with lower respiratory tract disorders

\section{SI. No Demographic variables Frequency Percentage}

II Alternative therapy practices

\begin{tabular}{|c|c|c|}
\hline Ayurveda & 0 & 0 \\
\hline Homeopathy & 0 & 0 \\
\hline Naturopathy & 0 & 0 \\
\hline Siddha & I & 5 \\
\hline Unani & 0 & 0 \\
\hline None & 19 & 25 \\
\hline \multicolumn{3}{|l|}{ Medication intake } \\
\hline Bronchodilators & 14 & 70 \\
\hline Antibiotics & 5 & 15 \\
\hline NSAIDS & I & 5 \\
\hline
\end{tabular}


Table IG Frequency and percentage distribution of life style practices among patients with lower respiratory tract disorders

\begin{tabular}{llll}
\hline SI. No & Demographic variables & Frequency & percentage \\
\hline I3 & Life style practices & & \\
& Breathing & $\mathrm{I}$ & $\mathrm{I}$ \\
& Aerobic & 0 & 0 \\
& Yoga & 4 & 20 \\
& Meditation & 0 & 0 \\
& others & 15 & 75 \\
\hline
\end{tabular}

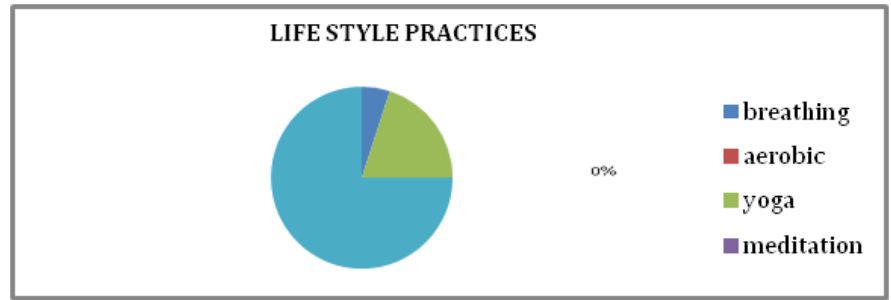

Table 2 Frequency and percentage distribution of pre-test and post test scores of dyspnea scale among patients with lower respiratory tract disorders

\begin{tabular}{|c|c|c|c|c|c|c|c|}
\hline \multirow[t]{2}{*}{ SI. No } & \multicolumn{2}{|c|}{ Dyspnea Scale } & \multicolumn{2}{|l|}{ Pre-Test } & \multicolumn{2}{|l|}{ Post-Test } & \multirow{2}{*}{$\begin{array}{l}\text { Pre-test vs. post test } \\
\text { P value }\end{array}$} \\
\hline & & & Frequency & Percentage & Frequency & Percentage & \\
\hline & a) & normal & 5 & 25 & 12 & 60 & \\
\hline & b) & poor & 15 & 75 & 8 & 40 & 0.008 \\
\hline
\end{tabular}

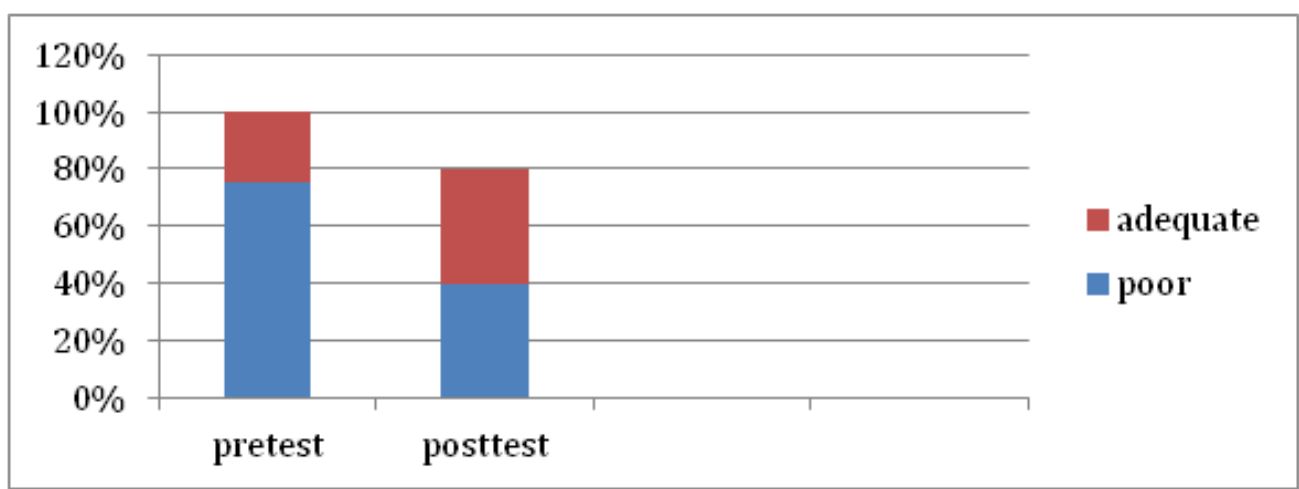

Table 3 Association of dyspnea grading with selected demographic variables $\mathrm{s}^{* *}$-significant, NS ${ }^{* *}$-non significant

\begin{tabular}{|c|c|c|c|c|c|c|}
\hline \multirow{2}{*}{ SI. No } & \multirow{2}{*}{ Demographic variables } & \multicolumn{4}{|c|}{$\begin{array}{l}\text { Dyspnoea grading of patient with lower respiratory tract } \\
\text { disorder }\end{array}$} & \multirow{2}{*}{$\mathbf{X} 2$ value } \\
\hline & & Poor & & & & \\
\hline & & $\mathrm{F}$ & $\%$ & $\mathrm{~F}$ & $\%$ & \\
\hline \multirow[t]{4}{*}{ I } & Age & & & & & $X 2=6.188$ \\
\hline & $20-40$ & 2 & 10 & 2 & 10 & $d f=2$ \\
\hline & $4 \mid-60$ & 12 & 60 & I & 5 & $\mathrm{P}=0.045$ \\
\hline & 61 and above & I & 5 & 2 & 10 & $S^{* *}$ \\
\hline \multirow[t]{4}{*}{2} & Gender & & & & & $X 2=3.590$ \\
\hline & & & & & & $d f=I$ \\
\hline & Male & 8 & 40 & 5 & 25 & $\mathrm{P}=0.058$ \\
\hline & Female & 7 & 35 & 0 & 0 & $S^{* *}$ \\
\hline \multirow[t]{3}{*}{3} & Educational status & & & & & $X 2=4.711$ \\
\hline & Non literate & 3 & 15 & 2 & 10 & $d f=I$ \\
\hline & primary & 10 & 50 & 2 & 10 & $P=0.194$ \\
\hline
\end{tabular}


Table continued

\begin{tabular}{|c|c|c|c|c|c|c|}
\hline \multirow[t]{2}{*}{ SI. No } & \multirow[t]{2}{*}{ Demographic variables } & \multicolumn{4}{|c|}{$\begin{array}{l}\text { Dyspnoea grading of patient with lower respiratory tract } \\
\text { disorder }\end{array}$} & \multirow[t]{2}{*}{ X2 value } \\
\hline & & Poor & & & & \\
\hline & secondary & 2 & 10 & 0 & 0 & NS** \\
\hline & graduate & 0 & 0 & I & 5 & \\
\hline \multirow[t]{5}{*}{4} & Occupational status & & & & & $X 2=1.908$ \\
\hline & Un-employed & 3 & 15 & 2 & 10 & $d f=2$ \\
\hline & Self-employed & II & 55 & 2 & 10 & $P=0.385$ \\
\hline & Employment in public sector & I & 5 & I & 5 & NS** \\
\hline & Employment in private sector & 0 & 0 & 0 & 0 & \\
\hline \multirow[t]{5}{*}{5} & Area of work & & & & & $X 2=0$ \\
\hline & Cotton industry & 0 & 0 & 0 & 0 & $d f=0$ \\
\hline & Chemical factory & 0 & 0 & 0 & 0 & $P=0$ \\
\hline & Mining industry & 0 & 0 & 0 & 0 & NS** \\
\hline & Others & 15 & 75 & 5 & 25 & \\
\hline \multirow[t]{4}{*}{6} & Duration of illness & & & & & $X 2=1.467$ \\
\hline & $<2$ years & 8 & 40 & 25 & 10 & $\mathrm{df}=2$ \\
\hline & $2-3$ years & 5 & 25 & 2 & 10 & $P=0.48$ \\
\hline & $>2$ years & 2 & 10 & 0 & 0 & NS** \\
\hline \multirow[t]{4}{*}{7} & Types of workers & & & & & $X 2=1.600$ \\
\hline & Sedentary workers & 3 & 15 & 2 & 10 & $d f=2$ \\
\hline & Moderate workers & 9 & 45 & 3 & 15 & $P=0.449$ \\
\hline & Heavy workers & 3 & 15 & 0 & 0 & NS** \\
\hline \multirow[t]{5}{*}{8} & Co-morbid illness & & & & & $X 2=2 . .400$ \\
\hline & Anemia & 3 & 15 & 2 & 10 & $d f=3$ \\
\hline & $\mathrm{IHD}$ & 4 & 20 & 0 & 0 & $P=0.494$ \\
\hline & Thyroid disorder & I & 5 & 0 & 0 & NS** \\
\hline & None & 7 & 35 & 3 & 15 & \\
\hline \multirow[t]{4}{*}{9} & Smoking Habit & & & & & $\times 2=4.444$ \\
\hline & & & & & & $d f=I$ \\
\hline & Yes & 8 & 40 & 0 & 0 & $\mathrm{P}=0.035$ \\
\hline & No & 7 & 35 & 5 & 25 & $\mathrm{~S}^{* *}$ \\
\hline \multirow[t]{4}{*}{10} & Tobacco chewing habit & & & & & $X 2=0.000$ \\
\hline & & & & & & $d f=I$ \\
\hline & Yes & 12 & 60 & 4 & 20 & $P=1$ \\
\hline & No & 3 & 15 & 1 & 5 & NS** \\
\hline \multirow[t]{7}{*}{ II } & Alternative therapies if any & & & & & $X 2=0.35 \mathrm{I}$ \\
\hline & Ayurveda & 0 & 0 & 0 & 0 & $d f=I$ \\
\hline & Homeopathy & 0 & 0 & 0 & 0 & $P=0.554$ \\
\hline & Naturopathy & 0 & 0 & 0 & 0 & NS** \\
\hline & Siddha & I & 5 & 0 & 0 & \\
\hline & Unani & 0 & 0 & 0 & 0 & \\
\hline & None & 14 & 70 & 5 & 25 & \\
\hline \multirow[t]{4}{*}{12} & Medication Intake & & & & & $X 2=0.495$ \\
\hline & Bronchodilators & 10 & 50 & 4 & 20 & $d f=2$ \\
\hline & Antibiotics & 4 & 20 & 1 & 5 & $P=0.78 \mathrm{I}$ \\
\hline & NSAIDS & & & & & NS** \\
\hline \multirow[t]{6}{*}{13} & Life style practices & & & & & $X 2=2.222$ \\
\hline & Breathing & I & 5 & 0 & 0 & $\mathrm{df}=2$ \\
\hline & Aerobic & 0 & 0 & 0 & 0 & $P=0.329$ \\
\hline & Yoga & 4 & 20 & 0 & 0 & NS** \\
\hline & Meditation & 0 & 0 & 0 & 0 & \\
\hline & Others & 10 & 50 & 5 & 25 & \\
\hline
\end{tabular}

24 describe the association of dyspnoea grading among patient with lower respiratory tract disorder with selected demographic variables. There was a significant association of age, gender and smoking habit at $p<0.05$. Hence it showed that dyspnea increases among age, gender, and smoking habit among patient with lower respiratory tract disorder. ${ }^{9}$ 


\section{Discussion}

The objective was to evaluate the effectiveness of balloon therapy on level of dyspnoea among patients with lower respiratory tract disorders during posttest. On conducting post-test to the selected 20 $12(60 \%)$ was found to be non dyspnoeic, $8(40 \%)$ were dyspnoeic. There was no association with most of the demographic variables like educational status, occupational status area of work, type of workers, co-morbid illness, tobacco chewing, alternative therapies, medication intake and life style practices with respiratory status which includes dyspnea scale. Whereas there was an association with age, gender, smoking habit and duration of illness with the level of dyspnea., ${ }^{4,12,13}$

\section{Conclusion}

Exercise is the medicine for creating change in a person's physical, emotional and mental status. Thus the balloon therapy is an empirical evidence to follow it in day to day practice by patients with respiratory tract disorders..$^{10,14,15}$

\section{Acknowledgments}

None.

\section{Conflict of interest}

The authors declare that there is no conflict of interest.

\section{References}

1. Joyce M Black. Medical Surgical Nursing Clinical management of positive outcomes. $6^{\text {th }}$ ed. Elsevier Publications;2004;1:1651-1746.

2. Brunner, Suddarth. Medical Surgical Nursing. $10^{\text {th }}$ ed. USA: Lippincott; 2004. p. 516-633.

3. Lewis, Heitkemper. Medical Surgical Nursing. $6^{\text {th }}$ ed. USA: Mosby; 2004.
4. Morillas HN, Zariwale M, Knowles MR. Genetic causes of Bronchiectasis: Primary CIliary Dyskinesia. Journal of Respiratory Disorders. 2007;72(3):253-263.

5. Black MJ, Jane Hokanson Hawks. Medical Surgical Nursing Clinical Management for Postive Outcome. $7^{\text {th }}$ ed. India: Elseiver publications, New Delhi; 2004.

6. Flick MR, Moody LE, Block AJ. Effect of ultrasonic nebulization on arterial oxygen saturation in chronic obstructive pulmonary disease. Chest. 1977;71(3):366-370.

7. Chauhan AJ, McLindon JP, Dillon P, et al. Regular balloon inflation for patients with chronic bronchitis: a randomised controlled trial. BMJ. 1992:304(6843):1668-1669.

8. Polit. Essentials of Nursing Research: Appraising Evidence for Nursing Practice. $9^{\text {th }}$ ed. USA: Lippincott, Philadelphia; 2011:268-269.

9. Burns Nancy. Understanding Nursing Research. $3^{\text {rd }}$ ed. UK: WB Saunders company, London; 1999.

10. Benzo R, Kelley GA, Recchi L, et al. Compliations of Lung Resection and Exercise Capacity: a Meta Analysis. Respire. 2007;101(8):1790-1797.

11. PS Sunder Rao. An Introduction to Biostatistics. $3^{\text {rd }}$ ed. India: hail of Indira Publications; Prentice.

12. Kumar V, Abbas AK, Fausto N, et al. Pulmonary basis of disease. $7^{\text {th }}$ ed. India: Elseiver, New Delhi; 2004.

13. Brun PP, Boer AH. Nebulisation in worsenity of Chronic Obstructive Lung Disease Importance of Anticholinergic Agents. The Multicenter Group International Journal of Medicine. 2007;43(4):543-623.

14. Crofton J. Respiratory Tract Disease: Diagnosis and Treatment of Bronchiectasis. I Diagnosis. British Medcine Journal. 2002;8(54):721726.

15. Lee SC, Sin SH, Jung JY. The effects of balloon blow-ups and upper abdominal exercise on respiratory rehabilitation. J Kor Phys Ther Sci. 2011;18:17-24 